\title{
References
}

1) T. Okamoto, K. Shudo, S. Takahashi, E. Kawachi, and Y. Isogai, Chem. Pharm. Bull., 29, 3747 (1981).

2) J.J. McDonald, N.J. Leonard, R.Y. Schmitz, and F. Skoog, Phytochemistry, 10, 1429 (1971); F. Skoog, R.Y. Schmitz, R.M. Bock, and S.M. Hecht, ibid., 12, 25 (1973).

3) T. Okamoto, K. Shudo, and Y. Isogai, "Plant Growth Substances (IPGSA 1973)," Hirokawa Publishing Co., Tokyo, 1974, p. 447.

4) S. Takahashi, T. Yatsunami, K. Shudo, T. Okamoto, K. Yamada, and Y. Isogai, Chem. Pharm. Bull., 26, 2286 (1978).

5) S.M. Hecht, R.M. Bock, R.Y. Schmitz, F. Skoog, and N.J. Leonard, Proc. Natl. Acad. Sci., USA. 68, 2608 (1971).

6) H. Iwamura, T. Ito, Z. Kumazawa, and Y. Ogawa, Phytochemistry, 14, 2317 (1975).

7) N.P. Kefford, J.A. Zwar, and M.I. Bruce, "Biochemistry and Physiology of Plant Growth Substances," eds. by F. Wightman and G. Setterfield, Runge Press, Ltd., Ottawa, 1968, pp. 61-69.

\author{
Faculty of Pharmaceutical Sciences, \\ University of Tokyo, \\ Bunkyo-ku, Tokyo, \\ College of General Education, \\ University of Tokyo, \\ Meguro-ku, Tokyo
}

Received August 27, 1981

\author{
FumiYa KUROSAKI \\ SOSHIRO TAKAHASHI \\ KoICHI SHUdo \\ Toshiniko OKamoto*
}

Yo Isog AI

\section{Reaction of Benzene with Diphenyl Sulfoxides}

Diphenyl sulfoxide reacted with benzenes in the presence of trifluoroacetic anhydride and trifluoromethanesulfonic acid to yield triphenylsulfonium ions in good yields. A new electrophilic species was proposed.

Keywords-_electrophilic aromatic substitution; diphenyl sulfoxide; triphenylsulfonium salt; trifluoromethanesulfonic acid; benzene

The most widely known reaction of benzene is the substitution by electrophilic species. ${ }^{1)}$ The quest for new electrophiles has been overcome by employing strong acids or suitable leaving groups. ${ }^{1)}$ The iminium-benzenium dication produced from $\mathrm{N}$-phenylhydroxylamine in the reaction catalyzed by trifluoromethanesulfonic acid (TFSA) is an example of new electrophiles which react with benzene under mild conditions. ${ }^{2}$ (The phenoxenium ion prepared by elimination of sulfonamide as the nucleofungal leaving group, also reacts with benzene. ${ }^{3)}$ This paper describes a discovery of a new electrophilic species which can react with benzene easily.

Sulfoxide, on acylation, gives an acyloxysulfonium ion. In the Pummerer type reactions, a proton abstraction on $\alpha$-carbon atom and the subsequent elimination of an acyloxy group gives ion pairs; carbonium ion and acetate anion. A nucleophilic attack of acetate anion to the carbonium ion gives the product (eq. 1). ${ }^{4}$

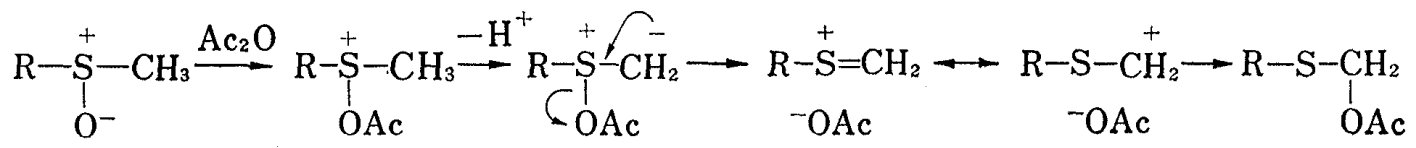


Since diphenyl sulfoxide (1) has no adjacent hydrogen, the common Pummerer reaction does not proceed. Therefore, a nucleophile can attack on the sulfur. Benzene is a relatively good nucleophile in a strong acid. Thus, diphenyl sulfoxide was allowed to react with benzene in the presence of TFSA, but the starting material recovered even after 6 h's reflux. However, 1 in benzene in the presence of TFSA and trifluoroacetic anhydride (but not the latter alone) smoothly reacted with benzene to give triphenylsulfonium ion.

A typical example is as follows. To a solution of diphenylsulfoxide 1 (606 $\mathrm{mg}, 3 \mathrm{mmol})$ in benzene $(10 \mathrm{ml})$ was added trifluoroacetic anhydride $(0.43 \mathrm{ml}, 6 \mathrm{mmol})$ and trifluoromethanesulfonic acid $(0.27 \mathrm{ml}, 3 \mathrm{mmol})$. The mixture was stirred at $0^{\circ} \mathrm{C}$ for $30 \mathrm{~min}$, and the temperature of mixture was raised to $20^{\circ} \mathrm{C}$. Triphenylsulfonium salt was gradually separated out within $1 \mathrm{~h}$. After $1 \mathrm{~h}$, benzene was decanted, and the residual colorless oil was solidified with addition of ether. The precipitates were washed with ether and recrystallized from dichloromethane-hexane to give triphenylsulfonium triflate 3 , as a white solid. The triflate was dissolved in methanol-water and was passed through a column of Amberlite IRA-400 resin (hydroxide form). Treatment of the eluent with aqueous potassium iodide gave pale yellow precipitates, which was crystallized from ethanol-hexane to give triphenylsulfonium iodide $4 \mathbf{a}$ in $88 \%$ yield. By the use of this method, several pure triarylsulfonium salts were prepared in good yields. The sulfonium salts synthesized are listed in Table I.

TABle I. Preparation of Triarylsulfonium Salts

\begin{tabular}{|c|c|c|c|c|c|c|}
\hline \multirow{2}{*}{$\begin{array}{l}\text { Arene } \\
\text { Benzene }\end{array}$} & \multirow{2}{*}{$\frac{\text { Products }}{\text { Triphenylsulfonium }}$} & \multicolumn{2}{|c|}{ Yield (\%) (triflate) } & \multicolumn{2}{|c|}{ Yield (\%) (iodide) } & \multirow{2}{*}{$\frac{\operatorname{mp}\left({ }^{\circ} \mathrm{C}\right)(\text { iodide })^{d)}}{248-250^{e)}}$} \\
\hline & & $\mathbf{3 a}$ & $95^{a)}$ & $4 a$ & $88^{b)}$ & \\
\hline Toluene & Diphenyl-4-tolyl- & $\mathbf{3 b}$ & $93^{a)}$ & $4 \mathrm{~b}$ & $85^{b)}$ & $249-252$ \\
\hline$o-X y l e n e$ & Diphenyl-3,4-dimethylphenyl- & $3 \mathbf{c}$ & $91^{a)}$ & $4 c$ & $80^{b)}$ & $200-201$ \\
\hline$m$-Xylene & Diphenyl-2,4-dimethylphenyl- & & $L^{c)}$ & $4 d$ & $83^{a)}$ & $243-244$ \\
\hline Mesitylene & Diphenyl-2,4,6-trimethylphenyl- & & _c) & $4 \mathbf{e}$ & $85^{a)}$ & $222-223$ \\
\hline
\end{tabular}

a) Yield based on diphenyl sulfoxide.

b) Yield based on sulfonium triflate 3.

c) Not isolated as solid.

d) Satisfactory elemental analyses were obtained.

e) lit. $250^{\circ} \mathrm{C}^{13)}$

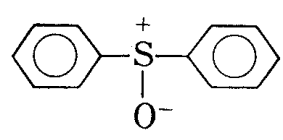

1
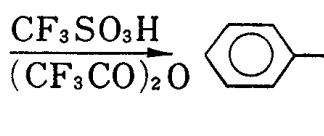

2<smiles>OC1(C(F)(F)F)CO[S+](c2ccccc2)C1</smiles>
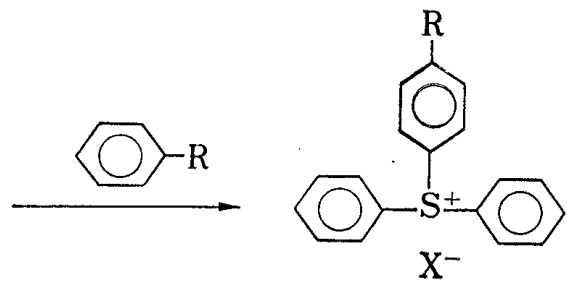

$3: \mathrm{X}^{-}=\mathrm{CF}_{3} \mathrm{SO}_{3}^{-}$

$4: \mathrm{X}^{-}=\mathrm{I}^{-}$

Chart 1

A plausible reaction pathway is shown in Chart 1 . Since the reaction did not proceed in the presence of TFSA alone or trifluoroacetic anhydride alone, probably a mixed anhydride, trifluoromethanesulfonic trifluoroacetic anhydride,,$^{5}$ participates in the reaction. 1 is acylated by the mixed anhydride, and the acyloxysulfonium ion 2 eliminates the acyl group with attack of benzene. The trifluoroacetoxy group is a very good leaving group, and an excess strong acid helps the leaving of the acyloxy group. ${ }^{6}$ ) Thus, the intermediate 2 is an electrophilic reagent with great reactivity. ${ }^{71}$ 
Among known methods for synthesis of triarylsulfonium ions, ${ }^{8-10)}$ the simplest is the aluminum halides-catalyzed reaction of sulfoxide with benzene. ${ }^{8)}$ Though the reaction conditions are drastic, the mechanism may be closely related to the present reaction. An example of a sulfonium ion postulated as an intermediate attacking arenes is dimethylsulfonium ion of type 5.11) However, the reagent reacts only with<smiles>CS(C)=S(C)N1CCC1=O</smiles>
phenol, and the mechanism is preferably interpreted by an intramolecular rearrangement of a sulfonium ion formed by the attack of phenolic oxygen. ${ }^{12)}$ From a synthetic stand-point, the reaction found here is the most promising method for synthesis of triarylsulfonium salts.

\title{
References and Notes
}

1) F. Effenberger, Angew. Chem. Int. Ed. Engl. 19, 151 (1980).

2) T. Okamoto, K. Shudo, and T. Ohta, J. Am. Chem. Soc. 97, 7184 (1975); K. Shudo, T. Ohta, and T. Okamoto, J. Am. Chem. Soc. 103, 645 (1981).

3) Y. Endo, K. Shudo, and T. Okamoto, J. Am. Chem. Soc. 99, 7721 (1977).

4) G.A. Russel and G.J. Mikol, "Mechanisms of Molecular Migrations," Vol. 1 ed. by B.S. Thyagarajan, New York, 1971, p. 245.

5) F. Effenberger and G. Epple, Angew. Chem. Int. Ed. Engl. 11, 299 (1972); A. Germain, A. Commeyras, and A. Casadevall, Bull. Soc. Chim. Fv. 1973, 2527, 2537.

6) T. Okamoto and K. Shudo, Tetrahedron Lett., 1973, 4533.

7) $\mathrm{Ph}_{2} \mathrm{~S}^{2+}$ is a possible active intermediate. However, the regioselectivity of the reaction with toluene was good, and biphenyl phenyl sulfide was not formed. These facts are incompatible with the participation of the very reactive intermediate.

8) C. Coutout and T.Y. Tung, C.R. Acad. Sci., 197, 1277 (1933); G.H. Wiegand and W.E. McEwem, J. Org. Chem., 33, 2627 (1933).

9) B.S. Wildi, S.W. Taylor, and H.A. Potratz, J. Am. Chem. Soc., 73, 1965 (1951); K.K. Anderson, M. Cinquini and N.E. Paramikolaou, J. Org. Chem., 35, 706 (1970).

10) P. Manya, A. Sekera, and P. Rumpf, Bull. Soc. Chim. France, 1971, 268.

11) E. Vilsmaier and W. Sprugel, Tetrahedron Lett., 1972, 625; P. Claus and W. Rieder, ibid., $1972,3839$.

12) P.G. Gassman and D.R. Amick, ibid., 1974, 889, 3463.

13) W.A. Bonner, J. Am. Chem. Soc., 74, 5078 (1952).

\author{
Faculty of Pharmaceutical Sciences, \\ University of Tokyo, \\ Bunkyo-ku, Tokyo 113, Japan
}

Received August 27, 1981

\author{
YASUYUKI ENDO \\ KoICHI SHUDO \\ Toshiniko Oкамото*
}

\section{High Performance Liquid Chromatographic Analysis of Sulfite using Malachite Green}

\begin{abstract}
A selective, sensitive and accurate determination of sulfite was proposed by high performance liquid chromatography (HPLC). The sulfite was converted quantitatively to an adduct by reacting with a triphenylmethane dye, malachite green (MG). The formation of adduct was complete, and the adduct was stable at the experimental conditions. Then, the adduct was submitted to HPLC. The working curve for sulfite was linear in the range from $2.0 \times 10^{-12} \mathrm{~mol}$ upto $1.2 \times 10^{-9} \mathrm{~mol}$.
\end{abstract}

